This allows some corneas (stored in liquid nitrogen at $-197^{\circ} \mathrm{C}$ for as long as eight years) to maintain a normal endothelium, which is valuable when tissue typed material is needed-for instance, when the rejection rate is high because the recipient has a heavily vascularised cornea. But the costs of establishing a bank of antigen-labelled corneas are formidable, which, together with the hazards of deep freezing and thawing, have greatly restricted its use. McCarey and Kaufmann then developed a medium for storage above zero, which was widely used, and particularly its most recent derivative $\mathrm{K}$ Sol. Corneas have also been stored in a tissue culture at room temperature in Denmark and in Minneapolis, ${ }^{i}$ but this is expensive, requires expert supervision, and inevitably carries a greater risk of infection.

The latest important innovation comes from East Grinstead, where the researchers have used recombinant human epidermal growth factor to produce in vitro replication of endothelial cells in 87 cadaver corneas from patients aged between 6 months and 80 years. ${ }^{3}$ Clearly defined mitotic figures in all states of cell division are seen throughout the endothelial layer. The endothelial population of donor corneal discs may thus be increased simply by incubating them for about four days in a tissue culture medium that is laced with the growth factor. The growth factor is potentially available in pure form and in unlimited quantities.

Other exciting possibilities suggest themselves. The growth factor might be added to standard short term media and so enlarge the scope for elective surgery: there might be time for HLA matching, which should reduce the many donor eyes that now go to waste. The growth factor might even be used to stimulate the decompensating endothelium of Fuch's dystrophy-perhaps by injecting it into the anterior chamber, and this might postpone or even avoid the need for keratoplasty.

PATRICK TREVOR-ROPER

Consultant Ophthalmic Surgeon,

London NW1 4LJ

1 Mueller FO, Casey TA, Trevor-Roper PD. Use of deep-frozen human cornea in full thickness grafts. Br Med f 1964;ii:473-5.

2 Doughman DJ, Van Horn D, Rodman WP, Byrnes P, Lindstrom RL. Human corneal endothelia layer repair during organ culture. Arch Ophthal 1976;94:1791-6.

3 Couch JM, Cullen P, Casey TA, Fabre JW. Mitotic activity of corneal endothelial cells in organ culture with recombinant human epidermal growth factor. Ophthalmology 1987;94:1-6.

\section{Red cell antibodies}

Since the discovery of the $\mathrm{Rh}(\mathrm{D})$ blood group its association with erythroblastosis fetalis (haemolytic disease of the newborn) has become well understood. ${ }^{12}$ The introduction of prophylactic anti-D immunoglobulin produced a dramatic fall in the incidence of the disease between 1969 and $1976 . .^{3-5}$ The fall has not, however, been maintained because some patients are not being offered prophylaxis and some are not given the anti-D immunoglobulin properly; another problem is spontaneous antenatal sensitisation. ${ }^{6}$

The decrease in rhesus isoimmunisation has produced a relative increase in the number of other red cell antibodies found in the sera of pregnant women. ${ }^{6-10}$ Most arise from the non-rhesus system. In general, they cause only mild haemolytic disease of the newborn but severe disease and stillbirths have been reported in association with anti-c, anti-Kell, anti-f(ce), anti-S, and anti-M antibodies. ${ }^{611-14}$ Anti-c antibody is the most likely to cause important disease, ${ }^{610}$ is but other antibodies that may harm the fetus have been listed by Beal. ${ }^{8}$

The incidence of non-rhesus red cell antibodies in pregnant women is difficult to define but seems to be about 2$5 \% ; .65-85 \%$ of this group are patients who are rhesus (D) positive. All pregnant women must therefore be tested for the antibodies. Their potential for causing haemolytic disease of the newborn is related to the type of antibody formed and its ability to cross the placenta. IgG antibodies (subclasses IgG1 and IgG3) are the most dangerous, whereas IgM antibodies have little effect. Many of these antibodies arise from previous blood transfusions. Paternal serum should be tested for the antigen, and if it is not found there is no risk of isoimmunisation.

The presence of the antigen in the father's serum may result in maternal antibodies appearing late in pregnancy. Bowell et al noted that a third of red cell antibodies, including anti-D antibodies, were not found in the first specimen tested, and often they did not appear until after week 28 of the pregnancy. ${ }^{10}$ In this group the resulting haemolytic disease of the newborn was less severe for both anti-D and anti-c antibodies. But preterm infants commonly suffer from jaundice, and any factors that increase the bilirubinaemiasuch as haemolytic disease caused by either rhesus or nonrhesus antibodies - will increase the chance that an exchange transfusion will be needed, a procedure that carries its own morbidity.

The most serious risk from red cell antibodies (other than anti-D antibodies) is not to the fetus but to the mothers. Indeed, any patient (not just pregnant women) whose serum contains irregular antibodies is at risk of a haemolytic reaction if given an emergency blood transfusion. Even $\mathrm{O}$ rhesus negative blood may be harmful if the patient's serum contains anti-c or anti-e antibodies as the donor serum will contain a double dose of these antigens. Red cell antibodies should therefore be identified well before labour or any elective surgical procedure to ensure so far as possible that compatible blood is available-few district hospital laboratories will hold adequate supplies because many red cell antibodies are now known to exist.

Although the case for testing all pregnant women for red cell antibodies seems proved, the frequency of performing these investigations has to be a balance between the benefit and an acceptable laboratory workload if results are to be obtained within a realistic timetable. A reasonable programme would be to test all patients at their first visit and again at 34 weeks' gestation. If anti-D, anti-c, or anti-Kell antibodies are detected and the consort's serum contains the antigen the tests will need to be done more often. A similar protocol for detecting other red cell antibodies does not seem justified unless regional and international variations dictate otherwise.

Amniocentesis at ultrasound scanning may be necessary for further evaluation of the fetal condition if the serum antibody titre is high or rising, and induction of labour before the expected date of confinement may sometimes be necessary.

The detection rate of red cell antibodies in serum is likely to increase and consequently the number of patients at risk will rise. All doctors who give blood products to any patient, especially premenopausal women, should remember that they are performing a "tissue transplant"-and it should perhaps be afforded the same respect as an organ transplant.

Consultant in Obstetrics and Gynaecology,

Alan Palmer Hull Health District, Hull HU2 8TD 
1 Wiener AS, Peters HR. Haemolytic reactions following transfusions of blood of the homologous group, with three cases in which the same agglutinogen was responsible. Ann Intern Med 1940;13:2306-21

2 Levine $\mathbf{P}$, Katzin EM, Burnham L. Isoimmunization in pregnancy, its possible bearing on the tiology of erythroblastosis fetalis. JAMA 1941;116:825-6.

3 Finn R, Clarke CA, Donohoe WTA, et al. Experimental studies on the prevention of $\mathrm{Rh}$ haemolytic disease Br Med f $1961 ;$; $1486-90$.

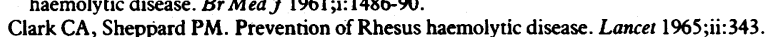

5 Freda VJ, Gorman JG, Pollack W, Robertson JG, Jennings ER, Sullivan JF. Prevention of Rh isoimmunization. FAMA 1967;119:390-4.

6 Tovey LAD. Haemolytic disease of the newborn-the changing scene. $\operatorname{Br} \mathcal{J}$ Obste Gynaecol 986;93:960-6.

Giblett ER. Blood group alloantibodies: an assessment of some laboratory practices. Transfusion 1977;17:299-308.

8 Beal RW. Non-rhesus (D) blood group isoimmunization in obstetrics. Clin Obstet Gynaecol 1979;6:493-508.

Hardy J, Napier JAF. Red cell antibodies detected in antenatal tests on Rhesus positive women in South and mid Wales, 1948-1978. Br f Obstet Gynaecol 1981;88:91-100.

10 Bowell PJ, Allen DL, Entwistle CC. Blood group antibody screening tests during pregnancy. $\mathrm{Br} \mathcal{F}$ Obstet Gynaecol 1986;93:1038-43.

1 Bowell PJ, Brown SE, Dike AE, Inskip MJ. The significance of anti-c alloimmunization in pregnancy. Brf Obstet Gynaecol 1986;93:1044-8.

12 Griffith TK. The irregular antibodies-a continuing problem. Am $\mathcal{f}$ Obstet Gynecol 1980;137; $174-5$.

13 Yoshida Y, Yoshida H, Tatsumi K, Asoh T, Hoshino T, Matsumoto A. Successful antibody elimination in severe $M$-incompatible pregnancy. $N$ Engl $\mathcal{Y}$ Med 1981;305:460-1.

4 Dacus JV, Spinnato JA. Severe erythroblastosis fetalis secondary to anti-Kpb sensitization. Am $\mathcal{J}$ Obstet Gynecol 1984;150:888-9.

15 Astrup J, Kornstad L. Presence of anti-c in the serum of 42 women giving birth to $c$ positive babies: Serological and clinical findings. Acta Obstet Gynecol Scand 1977;56:185-8.

\section{Acute renal failure: diagnosis of cause needed within hours}

Doctors may be so busy treating patients with acute renal failure with fluid and electrolyte replacement and, if necessary, dialysis that they may forget the importance of reaching an early diagnosis of the cause of the renal failure. This amnesia may cost patients their chance of having their renal failure reversed.

A recent prospective study of 250 patients with acute renal failure reminds us of the importance of making a histological diagnosis in those patients in whom specific treatment begun early might lead to reversal of acute renal failure. ${ }^{1}$ The proportion of patients with medical causes of acute renal failure appears to be rising, and it is these patients who will benefit most from early diagnosis by renal biopsy. ${ }^{23}$ Immunosuppressive treatment may be indicated in those with necrotising or crescentic glomerulonephritis, and recovery of renal function seems more likely if specific treatment is started before oliguria or anuria occur..$^{2.5}$

The suggestion that early diagnosis of medical acute renal failure by renal biopsy may help in managing acute renal failure is not new, ${ }^{2}$ but the recent finding that such an approach may lead to a histological diagnosis in up to a quarter of patients with acute renal failure presenting to a specialist unit suggests that the doctors responsible for the initial care of patients in a general ward should urgently determine whether a patient needs a biopsy. ${ }^{1}$ Carefully examining the clinical, nursing, and anaesthetic records plus examining the urine and excluding obstructive uropathy (by ultrasonography if necessary) will identify the $40-50 \%$ of patients with surgical renal failure and the few with obstetric renal failure. Clinical clues to glomerulonephritis may be rare in the remainder, although dipstick tests and microscopic examination of the urine may show the proteinuria, haematuria, and casts that point to this possibility. Renal biopsy in these patients is urgent, and they should be transferred to a specialist unit.

The reduced proportion of surgical and obstetric patients with acute renal failure probably reflects the recognition by anaesthetists of factors, such as fluid depletion, that predispose to acute renal failure. Further encouragement about the prognosis in this group of patients comes from evidence that the survival of patients with acute renal failure after repair of abdominal aortic aneurysms can be almost as good as that of all patients with surgical acute renal failure. ${ }^{1}$ The mortality from acute renal failure is appreciably higher in patients requiring mechanical ventilation and in those with sepsis and cardiorespiratory failure. Searching diligently for, and treating, foci of infection and avoiding measures that may precipitate cardiorespiratory failure early in the course of acute renal failure may help to reduce mortality.

The overall survival from acute renal failure has changed little in the past 20 years, although the range of underlying disease has changed appreciably. The increasing proportion of patients with medical acute renal failure calls for close collaboration between general physicians and specialist units. Failure to begin this collaboration within one or two hours of admitting a patient with acute renal failure to a general ward may deny him the chance of reversing his acute renal failure. The recent evidence that the mortality from medical acute renal failure may be lower than that from surgical acute renal failure provides strong support for management that places an emphasis on early diagnosis.

Physician, BUPA Hospital,

DAVID J WARREN

Havant PO9 5NP

1 Beaman M, Turney JH, Rodger RSC, McGonigle RJS, Adu D, Michael J. Changing pattern of acute renal failure. $O \mathcal{F} M e d$ (in press)

2 Wilson DM, Turner DR, Cameron JS, Ogg CS, Brown CB, Chantler C. Value of renal biopsy in acute intrinsic renal failure. $\mathrm{Br}$ Med $\mathrm{f}$ 1976;ii:459-61.

Beaufils M, Morel-Maroger L, Sraer J, Kanfer A, Kourilsky O, Richet G. Acute renal failure of glomerular origin during visceral abscesses. N Engl f Med 1976;295:185-8.

4 Heaf JG, Jorgensen F, Nielsen LP. Treatment and prognosis of extracapillary glomerulonephritis. Nephron 1983;35:217-24.

5 Courser WG. Idiopathic rapidly progressive glomerulonephritis. Am f Nephrol 1982;2:57-69.

\section{Tenosynovitis in industry: menace or misnomer?}

Tenosynovitis affecting the hand or forearm is now the second commonest prescribed industrial disease in Britain (the commonest is dermatitis). ${ }^{2}$ It is not always appreciated, however, that there are two distinct conditions commonly described as tenosynovitis that differ in their incidence, symptoms, signs, treatment, and prognosis. ${ }^{3.5}$ The first of these could be called true tenosynovitis-that is, inflammation of the synovial lining of a tendon sheath - and is rare and potentially serious. The second, which is known generally as peritendinitis crepitans, is inflammation at the musculotendinous junction that often extends well into the affected muscle. ${ }^{3-6}$ It is more common and much more benign. Assembly line workers who repeat the same movements up to 25000 times a day are vulnerable to both conditions. ${ }^{7-9}$ The incidence is difficult to establish as many studies do not state their diagnostic criteria, but most accept that true tenosynovitis is much less common than peritendinitis crepitans. ${ }^{2-59}$ The incidence of the latter varies considerably between different occupations from under $1 \%$ to over $50 \%$. $^{3}$

Both conditions are painful (particularly on resisted movement), and there is usually localised swelling, tenderness, and audible or palpable crepitus. The distinguishing feature is the site of the lesion: true tenosynovitis affects the synovial sheaths and is thus confined to the wrist and hand, where 